\title{
Monitoring of glaciers in the Polar Urals using remote sensing Data
}

\author{
Natalia Martynova ${ }^{1, *}$, Valentina Budarova ${ }^{1}$, Artem Sheremetinsky ${ }^{1}$, and Nikita Mezentsev ${ }^{2}$ \\ ${ }^{1}$ Tyumen Industrial University, 38, Volodarskogo St., 625000, Tyumen, Russia \\ ${ }^{2}$ University of Tyumen, 6, Volodarskogo St., 625000, Tyumen, Russia
}

\begin{abstract}
The development of technological progress provides more opportunities for indirect monitoring of changes in the environment. Remote sensing is one of The most accessible and reliable sources of information. In this work, we used satellite images from the Landsat family. The theoretical justification of the research question is given. The research methodology was developed. Collection and processing of satellite images for various time periods. A series of schematic maps based on remote sensing Data has been created. As a result of digitization of satellite images, 9 glacier contours were obtained by year. We determined the area of the Romantics glacier and found that it lost at least $60 \%$ of its original area. These studies were used to build a series of cartographic schemes that clearly show the reduction of the glacier area. It is concluded that the use of remote sensing allows you to solve problems, monitoring the object. The use of this method allows not only to save time for field work, but also material costs for expedition equipment and various equipment. This method can be tested on any objects.
\end{abstract}

\section{Introduction}

Glaciers are one of the indicators of climate change. They react sharply to the slightest changes in the atmosphere. Interest in monitoring glaciers is increasing as a result of rapid melting in many parts of the world. Some glaciers that are more exposed to melting require constant monitoring of their morphological parameters. Earth remote sensing (ERS) data helps to regularly monitor the fluctuations of the glacier. Observations of changes in glacier area are an important source for many studies [1-6].

Since the beginning of the second half of the 20th century, it has become acceptable to use satellite images to estimate the mass of fluctuations at the ends of glaciers and changes in the area of glaciation.

Research using remote sensing data has a number of advantages: the speed of obtaining satellite images of varying degrees of detail, a plausible image of the territory, and the ability to find images over a fairly long period of time. The disadvantages include the need for data processing, the ability to use specialized software systems.

In their research, V. G. Konovalov and V. A. Rudakov [7] use remote sensing data to determine the characteristics of glaciers. They demonstrated examples of finding the

\footnotetext{
* Corresponding author: natali.cherdanceva@mail.ru
} 
reflectivity of the surface of glaciers using ENVI SOFTWARE and remote sensing data from Landsat and TERRA spacecraft. Based on the results obtained, the movement of the moraine cover was analyzed, and data on the pulsation movements of the Pamir glaciers were obtained. Based on the results of the article, it was concluded that at the current time, the only source of obtaining completely reliable information, which is easy to track the dynamics of glacier morphology, is remote sensing data, which can be obtained fairly quickly. With the development of technologies, there is a huge probability that remote sensing data will acquire sufficient accuracy in studies aimed at monitoring sufficiently long periods of time.

In the paper "Modern changes in the area of glaciers in the Western part of the Nordenskiold Land (Svalbard archipelago)" Chernov, R. A., Murav'ev, A. Ya. [8]. Spacebased satellite materials such as Sentinel-2, but also the digital terrain model ArcticDEM, were used to monitor changes in the ice cover. The investigation revealed the reaction of the Nordenskiold mountain glaciation to changes in weather conditions in the 20th and early 21 st centuries. A significant decrease in the area of glaciers was revealed. Small mountain glaciers (up to $0.5 \mathrm{~km} 2$ ) have been most affected by changes in their area. According to the study, they have decreased by more than $70 \%$ of their area. While glaciers located in high valleys, lost about $30 \%$ of the area. In total, the total ablation reached 169.5 square kilometers, which is approximately $50 \%$ of the total area.

Chistyakov K. V., Ganyushkin D. A., Kurochkin Yu. N. in their study "Current state and dynamics of Nival-glacial systems of the Mongun-Taiga and Tavan-Bogdo-Ola massifs" [9] for the purpose of monitoring, the method of route studies was used, GPS coordinates of glacier edges were used, landmarks were set on the outskirts of glaciers, which makes it possible to most clearly establish the dynamics of ablation or accumulation of ice. A secondary source for them were satellite images Landsat 7.8; Spot 2.5. They did not use remote sensing as the main material, because they had the opportunity to make an expedition to the research area.

In order to achieve the most accurate results, it is necessary to equip expeditions that will perform measurements, but this leads to huge expenses in terms of money and time. Satellite images have every chance to significantly reduce the cost of research. Therefore, the technology of ultra-high-quality systems allows you to notice a large number of details, which gives an accurate image of the borders.

Remote sensing allowed us to form the latest ways to study the reality of space. With their support, you can quickly create any map. Various combinations of satellite image channels make it possible to notice secret features of nature that are difficult to recognize. The development of technological processes is implemented in ultra-high-resolution satellites (GeoEye-1, WorldView-1, WorldView-2, WorldView-3, WorldView-4 with a resolution of $0.3-0.5 \mathrm{~m}$ ) [10]. More significant advantages of using satellite images are considered: the speed of their acquisition, the relevance of information, for example, a satellite image of a Landsat-8 satellite can be obtained every 16 days [11].

From the authors ' point of view, the ideal remote sensing scheme [12] is shown in figure 1. according to A. M. Chandra: "Its elements are considered to be the electromagnetic radiation generator, the radiation propagation procedure and its connection with the object, the response signal, marking data and issuing it to customers. In this modification, the source produces high-energy electromagnetic radio radiation in absolutely the entire spectrum of wavelengths, while the radiation saturation is considered a known value that does not depend on the wavelength in any way. Radiation does not interact with the atmosphere in any way and propagates through it without loss of energy. The incident radio radiation interacts with the object, resulting in reflected or secondary radiation of its own, homogeneous in the entire spectrum of wavelengths." [13]. 


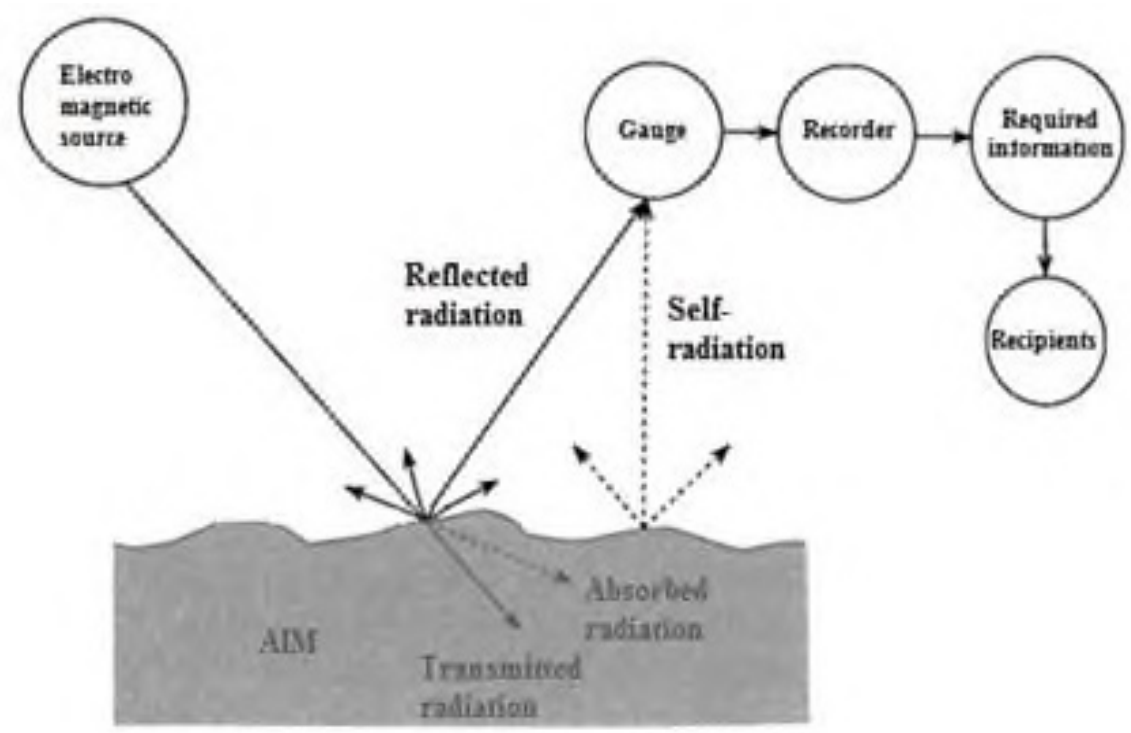

Fig. 1. Earth remote sensing scheme (Volkodaeva M. V., Volodina Ya. A., Lomtev A. Yu., Noskov S. N.).

There are many reasons why an ideal remote sensing system does not exist. For example, it is impossible to invent a perfect sensor that detects all the waves in the electromagnetic spectrum, even without sufficient experience to work with space images. The intensity of electromagnetic waves is also caused by the presence of various gases in the atmosphere [14]. Therefore, various studies have been conducted on a number of issues [15-18].

All of the above determines the relevance of the topic. The practical significance of monitoring glaciation using GIS technologies is that it is possible, without making expensive expeditions, to obtain fairly accurate data on changes in the area of glaciation, and it is also possible to predict its further changes. Even the final data can be used in more serious scientific research.

The object of research: the Romantics glacier, located in the polar Urals.

Subject of research: changes in the glacier area from 1986-2018.

Objective: to assess changes in the ice cover of the Romantics glacier in 1986-2018.

Research problem:

1) conduct a theoretical justification;

2) develop a research methodology;

3) collect and process satellite images for different time periods;

4) create a series of maps based on remote sensing data.

Characteristics of the research object: the polar Urals is located in the extreme NorthEast of the European territory of the Russian Federation and from mount Kolokolnya in the South-West to mount Konstantinov Kamen in the North-East.

Glaciers in the polar Urals have. snow line in these latitudes at an altitude of approximately 1700 meters. Glaciers of the Polar Urals exist below this level, for example, the Romantics Glacier (Fig.2), located near mount Rayiz, is located at an elevation of 1100 meters from sea level. 


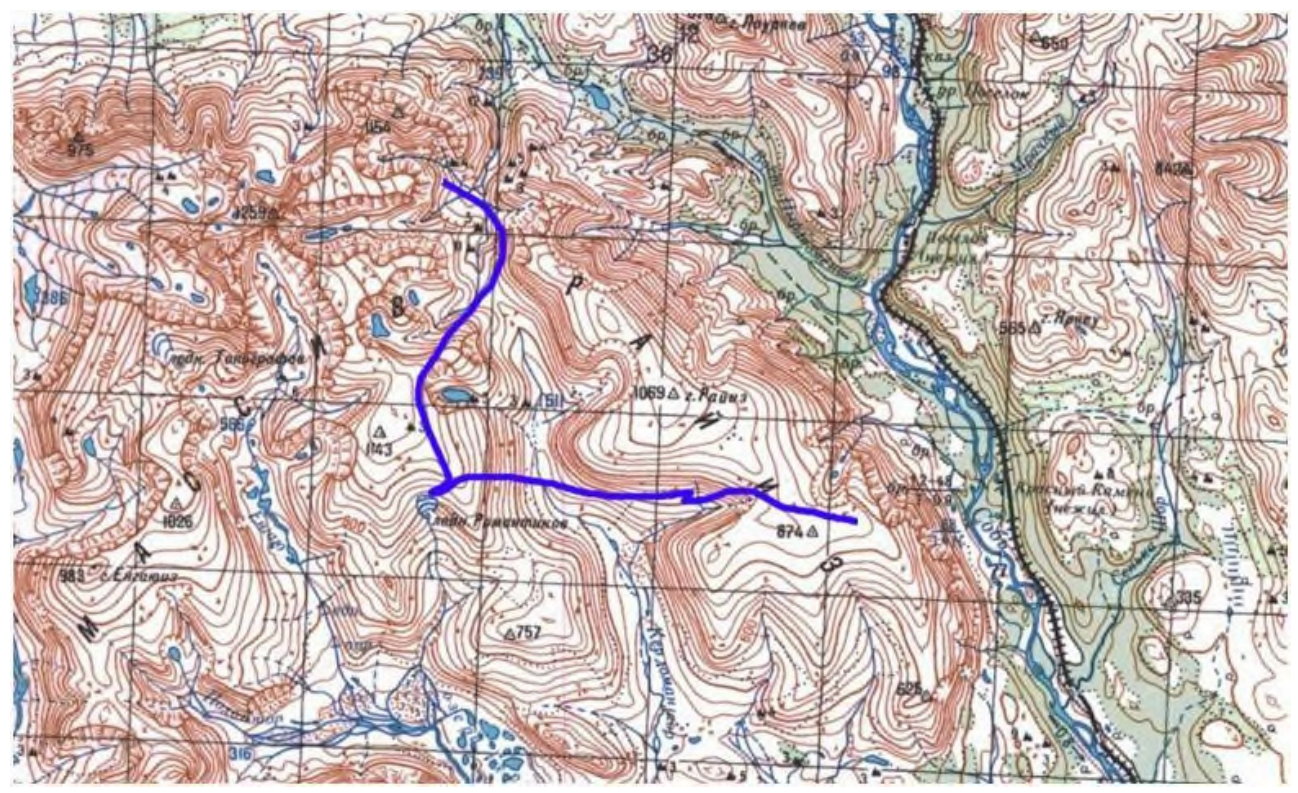

Fig. 2. Location Of The Romantics Glacier (https://www.exje.ru/polar-transural-razvedka).

\section{Methods}

The scheme of the chosen research method is shown in figure 3 in the author's algorithm.

\begin{tabular}{|c|}
\hline The installation of GIS software \\
\hline Search for satellite images \\
\hline Preprocessing of satellite images \\
\hline Uploading satellite images to GIS \\
\hline The digitized boundaries of the glacier \\
\hline Getting data about the area for years \\
\hline Creating an area graph \\
\hline The creation of schematic maps \\
\hline
\end{tabular}

Fig. 3. Diagram of the research methodology (author's algorithm).

To work with satellite images and vector data, the open geographic information system Quantum GIS Desktop (QGIS) is used. QGIS is a cross-platform GIS, which allows you to 
use it on various operating systems. QGIS is a user-friendly GIS program with General features and capabilities.

To monitor the decrease in the area of the Romantics glacier, multispectral satellite images of Landsat 4-5, 7, 8 were obtained for the study area from 1986 to 2018. Materials obtained from the official website of the us geological survey https://earthexplorer.usgs.gov.

The first stage is the preparation of satellite images for digitization. Processing of images using Pan-sharpening, i.e., to synthesize the multispectral bands with the panchromatic. After performing Pan-sharpening, a color image with increased spatial resolution is obtained. Pan-sharpening is performed using QGIS program modules. Atmospheric correction of images was performed in order to minimize the influence of clouds and to more accurately digitize the border of the Romantics glacier.

Second stage. To monitor the decrease in the area of the Romantics glacier, Landsat 4-5, 7, 8 multispectral satellite images were obtained for the study area over a period of 32 years (1986-2018). The materials were taken from the US geological survey website https://earthexplorer.usgs.gov.

Third stage. First, satellite images need to be prepared for digitization.to do this, you need to perform the Pansharpening procedure, that is, synthesize multispectral channels with a panchromatic channel that has a higher spatial resolution. as a result of this operation, we will get a color image with an increased spatial resolution. To do this, you will use one of the many modules of the QGIS program, which will allow you to perform this procedure most simply. Atmospheric correction of satellite images will be carried out in order to minimize the impact of clouds and it would be possible to more accurately digitize the borders of the Romantics glacier.

Fourth stage. Download of the synthesized satellite images in geographic information systems, with the aim of digitizing them in the future. You must create Shape files that specify the attributes of future polygons. The freely distributed cross-platform geographic information system Quantum GIS Desktop 3.10.2 (QGIS) will be used for this task.

Fifth stage. the digitized boundaries of the glacier. Using digitized polygons, we get the area values for different years. The data is analyzed in order to plot the reduction of the glacier area. Digitization of the glacier perimeter. This is done using the digitization tools in QGIS.

Sixth stage. For digitized polygons, using the field calculator, we get the area values for different years. calculations are also performed in QGIS.

Seventh stage. These data are analyzed in order to plot the reduction of the glacier area, where the years are marked on the horizontal axis and the glacier surface area in $\mathrm{km} 2$ on the vertical axis.

The eighth stage. In conclusion, based on the available data, namely polygons that contain the area values of the object under study, a QGIS map will be created that shows the size of the Romantics glacier over different years. A digital model of the relief of the Polar Urals from the funds of geodetic survey data was adopted as the topographical basis.

In conclusion, based on the obtained values of the area of the object under study, a mapdiagram of the size of the Romantics glacier for different years was created. After analyzing the maps, you can draw conclusions about the processes that occur with the glacier in different periods of time.

The advantages of the author's method are obtaining data in the shortest possible time, cheap production of works, since all data is taken from open sources, and the use of free distributed GIS.

The disadvantages are that compared to field observations, the author's method is less accurate and requires experience working with images. 


\section{Results}

The melting of glaciers is an urgent environmental problem. The use of satellite images not only helps to reduce the cost of research, but they can also be obtained in the shortest possible time. Technologies in the world are developing, new spacecraft are appearing. There are satellites with a resolution of $50 \mathrm{~cm}$ per pixel, for example, WorldView-1 [10]. This helps you see the smallest details of the area.

At the beginning of the study, images of the Romantics glacier for 1986-2018 were obtained from the official website of the US Geological survey (https://earthexplorer.usgs.gov). The site contains materials from various satellites, including Landsat satellites.

Using the site's geoportal technologies, the search area for the territory of the Romantics glacier is set. Next, search for satellite images using Landsat satellites is selected. We select all of them, because we need the earliest images of the area of interest. Setting the cloud cover parameters in the range from 0 to $20 \%$ in the "Additional criteria" tab. Click on the "Results" button and get a list of images according to the specified parameters (Fig. 4).

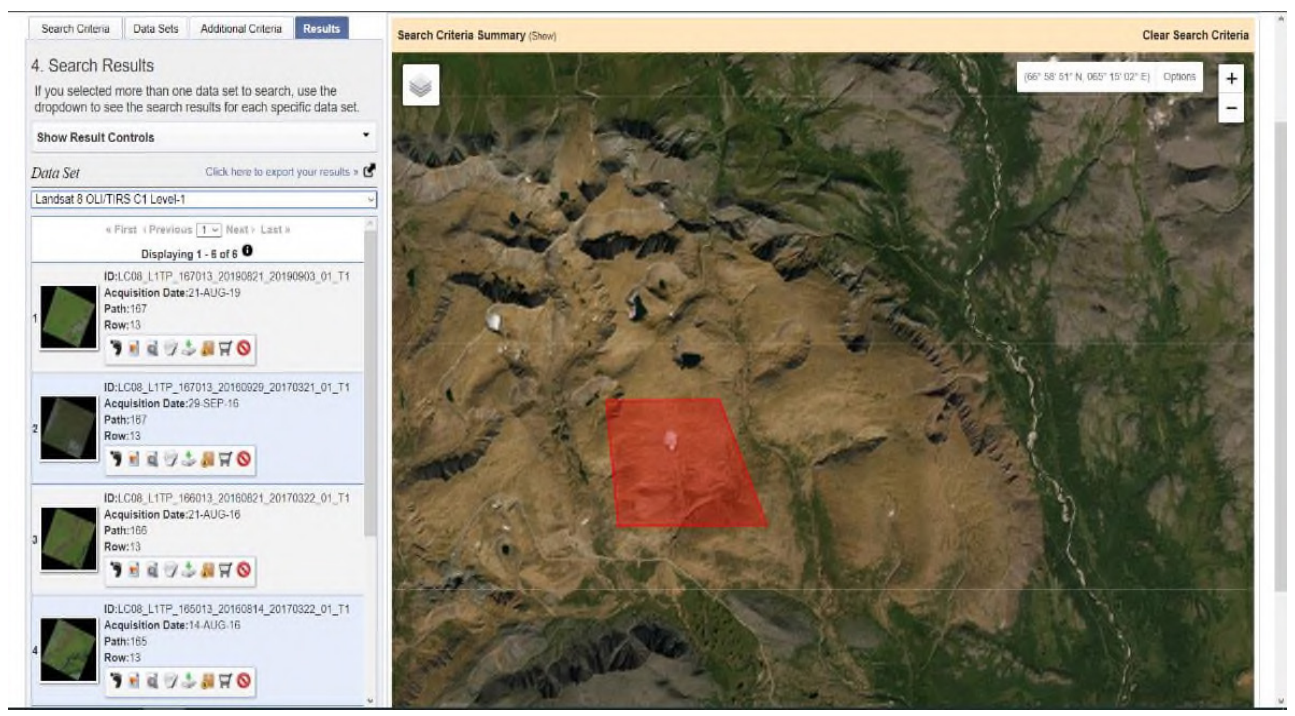

Fig. 4. Search results for satellite images.

Then we visualized the images in the browser using the "Show Browse Overlay" button. Next, download the images and select "Level-1 GeoTIFF Data Product". Table 1 shows the initial data of the study of the names of satellite devices, images, as well as their Path, Row and date of shooting. Figure 5 shows an example of a snapshot fragment for 2013.

Table 1. Used satellite images (authors).

\begin{tabular}{|c|l|l|l|l|}
\hline Satellite & \multicolumn{1}{|c|}{ Space image } & Path & Row & Shooting date \\
\hline \multirow{4}{*}{ Landsat 5 5 } & LM51660131986215AAA03 & 166 & 13 & 3.09 .1986 \\
\cline { 2 - 5 } & LT51650131989216KIS00 & 165 & 13 & 4.09 .1989 \\
\cline { 2 - 5 } & LT51660131993218KIS00 & 166 & 13 & 6.09 .1993 \\
\cline { 2 - 5 } & LT51650131997222KIS00 & 165 & 13 & 10.09 .1997 \\
\hline Landsat 7 & LE71650132000223SGS00 & 165 & 13 & 10.09 .2000 \\
\hline \multirow{2}{*}{ Landsat 5 } & LT51660132006222KIS01 & 166 & 13 & 10.09 .2006 \\
\cline { 2 - 5 } & LT51660132009214KIS01 & 166 & 13 & 2.09 .2009 \\
\hline \multirow{2}{*}{ Landsat 8 } & LC81660132016234LGN01 & 166 & 13 & 21.09 .2016 \\
\cline { 2 - 5 } & LC81660132018239LGN00 & 166 & 13 & 27.09 .2018 \\
\hline
\end{tabular}




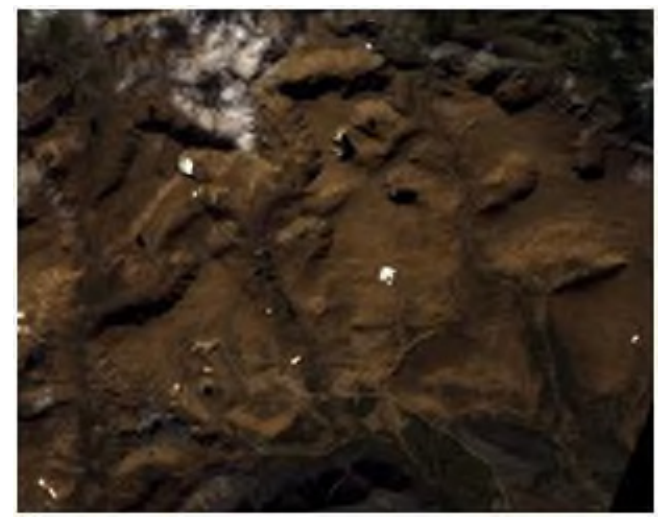

Fig. 5. Fragment of a satellite image for 2013.

The next step is the processing of images in QGIS. Pan-sharpening was performed with images from Landsat 7 and 8 satellites, since images from one of the channels (panchromatic) have a spatial resolution of $15 \mathrm{~m}$. In QGIS, images are synthesized using the "Semi-Automatic Classification Plugin", i.e. a combination of channels 4, 3, and $2-$ natural colors is applied. This operation was performed with images of the 7th and 8th generation of Landsat. The result is an image with natural colors, with increased spatial resolution. The next step was to add images to the program using the "Preprocessing" tab. After the channels are loaded, check the boxes "Apply DOS1 atmospheric correction" and "Perform pansharpening" to perform 2 operations - applying atmospheric correction and increasing the spatial resolution due to Pansharpening. This algorithm is performed with all Landsat images 7, 8. Figure 6 shows the result.

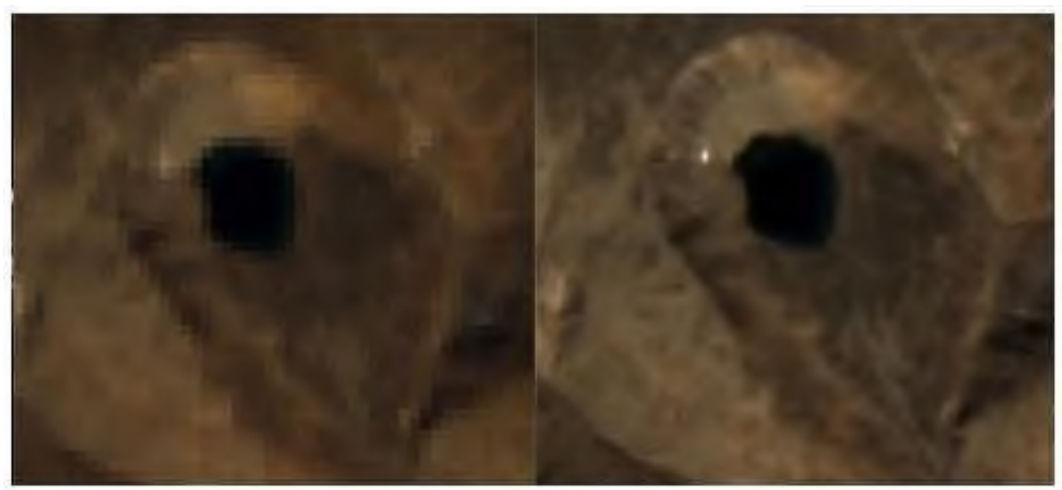

Fig.6. Result of atmospheric correction and Pansharpening.

To digitize the borders of the glacier, a Shapefile was created with the attributes of each polygon (Year - the year of the image that was digitized, and Area - the area calculated in square kilometers). The area is calculated in QGIS, using the field calculator. The formula is \$area/1000000.

After vectorizing the borders, the Shapefile is filled with data (table 2). 
Table 2. Glacier area Data for different years (authors).

\begin{tabular}{|c|c|}
\hline Year & Area, $\mathrm{km}^{2}$ \\
\hline 1986 & 0,3214 \\
\hline 1989 & 0,236 \\
\hline 1993 & 0,2184 \\
\hline 1997 & 0,2044 \\
\hline 2000 & 0,204 \\
\hline 2006 & 0,1725 \\
\hline 2009 & 0,1767 \\
\hline 2016 & 0,1062 \\
\hline 2018 & 0,1088 \\
\hline
\end{tabular}

According to the data from table 4, a graph was drawn up (Fig. 7), where the abscissa axis shows the year, and the ordinate axis shows the surface area of the glacier in square kilometers.

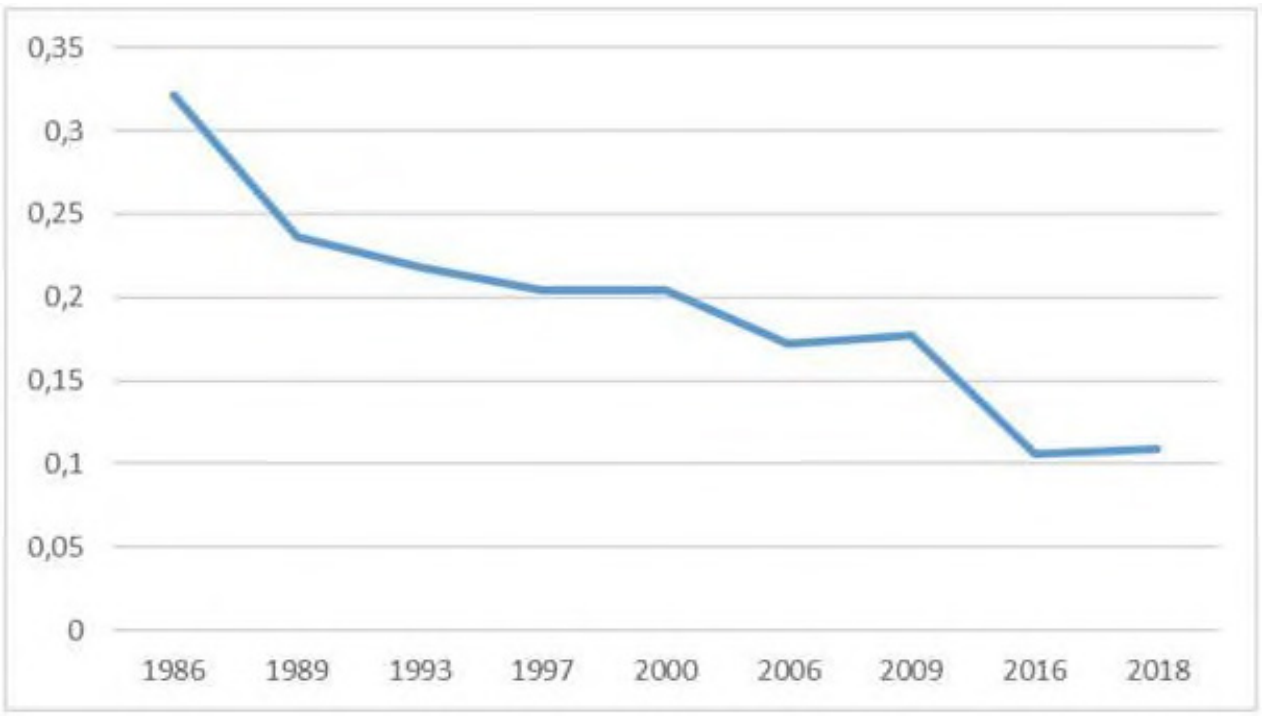

Fig. 7. Change in the area of the Romantics glacier.

After digitizing the borders, vector data containing polygons and polylines is added. They include horizontal lines, hydrography, vegetation, and soils designed in accordance with special topographic signs. As a result, 9 contours of the borders of the Romantics glacier were obtained by year.

The final stage involved creating several schematic maps at a scale of 1: 10000 (figure 8-10), in order to avoid information overload. 


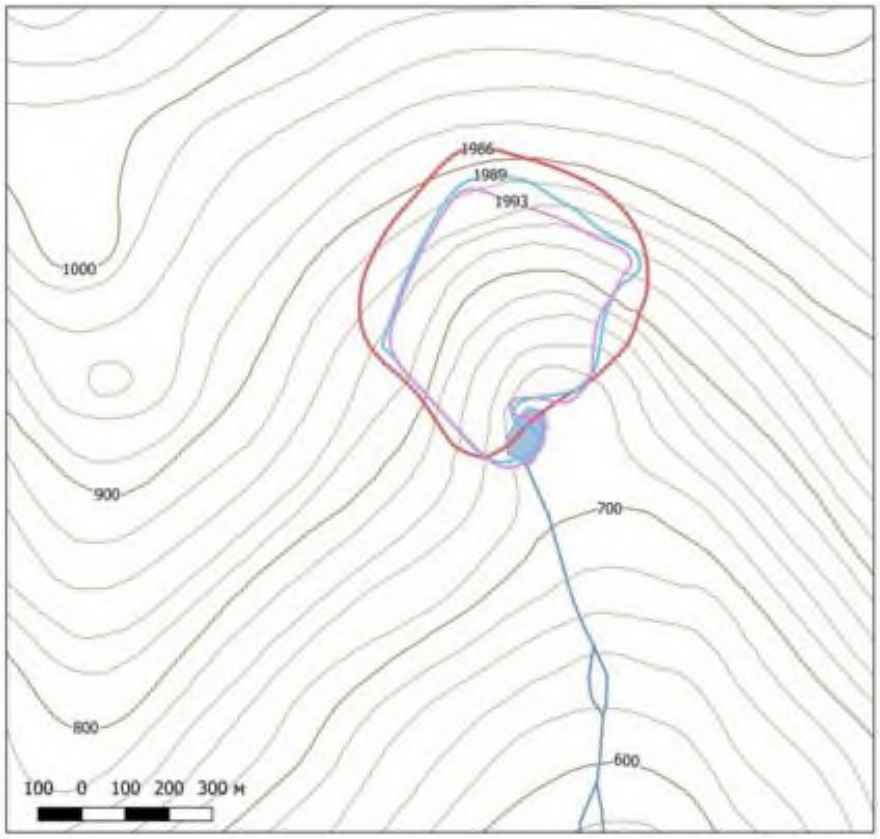

\section{Map symbols}

Year

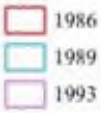

height lines

lakes

rivers

\begin{tabular}{|c|c|}
\hline Year & Area, $1 \mathrm{~km} 2$ \\
\hline 1956 & 0.3214 \\
\hline 1989 & 0.236 \\
\hline 1993 & 0.2184 \\
\hline
\end{tabular}

Fig. 8. Map-diagram of the dynamics of the Romantics square page 1 (authors).

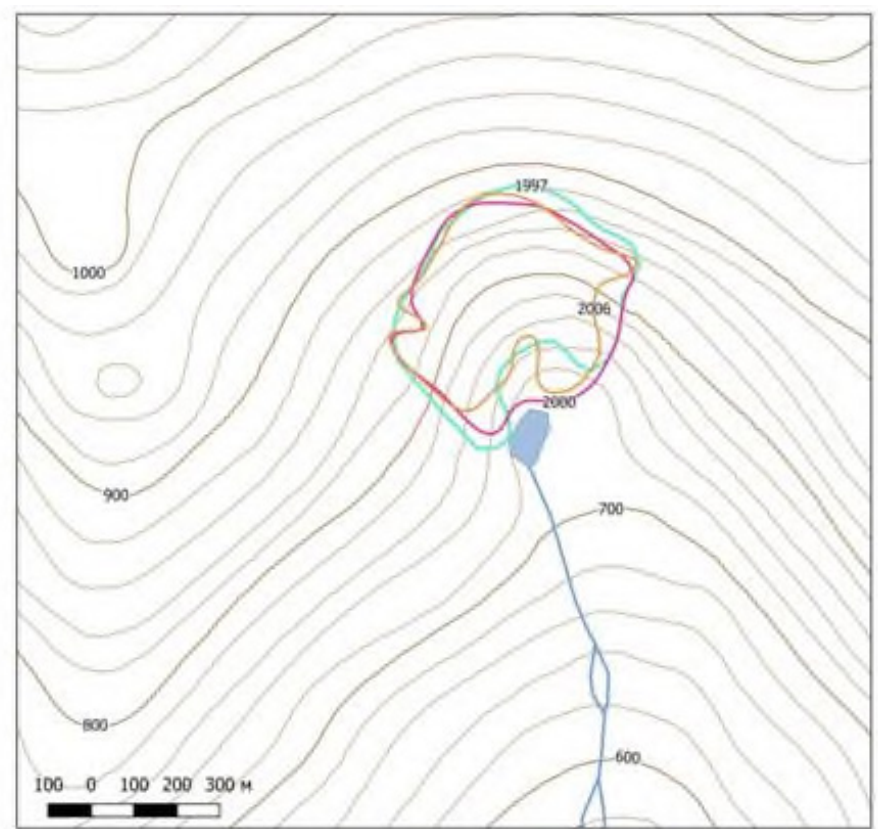

Map symbols

Year

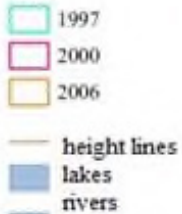

\begin{tabular}{|c|c|}
\hline Year & Area, km2 \\
\hline 1997 & 0.2044 \\
\hline 2000 & 0.204 \\
\hline 2006 & 0.1725 \\
\hline
\end{tabular}

Fig. 9. Map-diagram of the dynamics of the Romantics square page 2 (authors). 

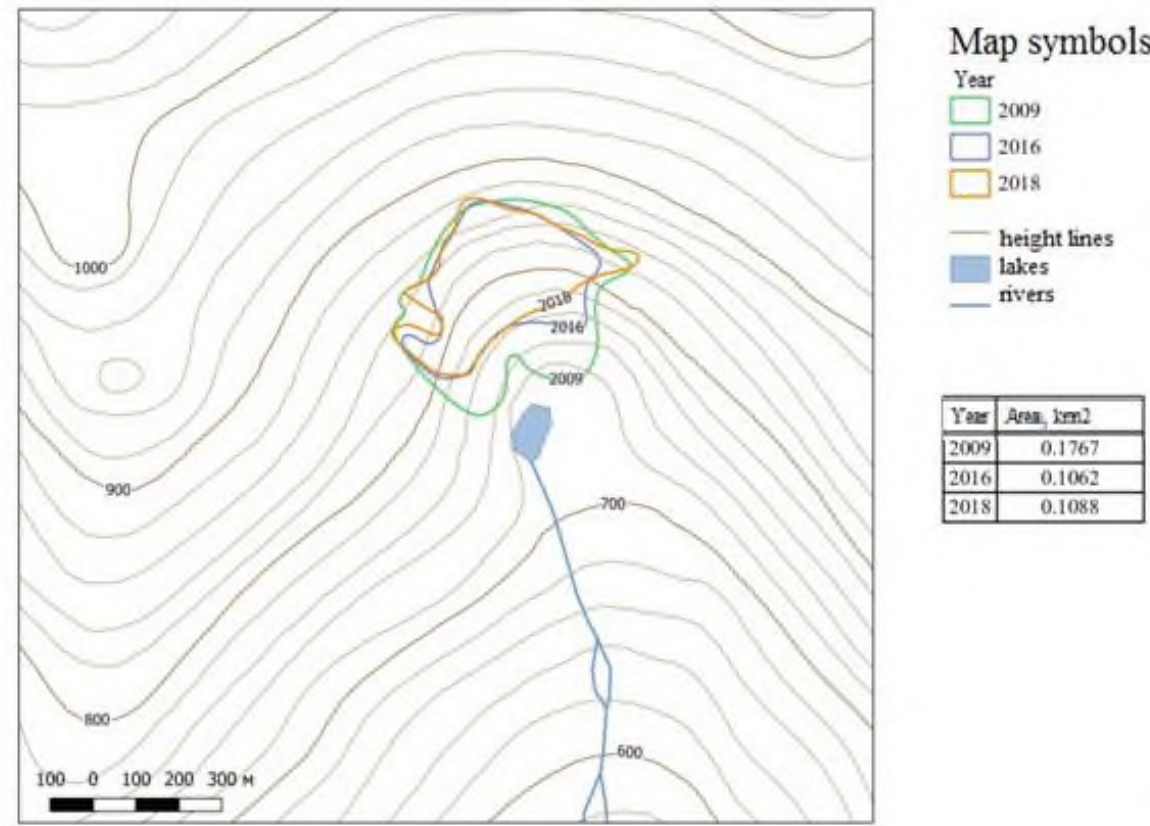

\begin{tabular}{|c|c|}
\hline Yon & Aran, im2 \\
\hline 2009 & 0.1767 \\
\hline 2016 & 0.1062 \\
\hline 2018 & 0.1088 \\
\hline
\end{tabular}

Fig. 10. Map-diagram of the dynamics of the Romantics square page 3 (authors).

Schematic maps contain elements: a map image, a table with areas, a legend, a scale, a frame, and a name.

According to the data obtained, it can be concluded that the Romantics glacier has lost at least $60 \%$ of its original area.

\section{Discussion}

Monitoring of environmental changes is possible using modern technologies. Remote sensing is one of the most accessible and reliable sources of information. Currently, there are many systems for remote sensing of the Earth. In this work, we used satellite images from the Landsat family. They were selected because they are publicly available and can be processed for more detailed information.

The study used QGIS software for pre-processing satellite images and working with vector data. The advantage of this GIS is its cross-platform nature, free distribution, and modularity, which allows you to replace several programs with a single plugin.

As a result of digitization of satellite images, 9 contours of glaciers corresponding to different years were obtained. According to a number of maps, the reduction in the area of the glacier is quite clearly visible. According to them, it was possible to determine the area of the Romantics glacier and establish that since the beginning of observations, it has lost at least $60 \%$ of its original area.

All this together allows us to conclude that the use of remote sensing allows us to solve problems in which it is necessary to monitor the object. In addition, using this method can not only save time on field work, but also material costs for expedition equipment and various equipment. Therefore, this method can be proposed for studying other glaciers of any territory. 


\section{References}

1. P. Satyanarayana, E. Siva Shankar, E. Amminedu, N.V. Babu, Proceedings of International Conference on Remote Sensing for Disaster Managemen, 535-550 (2019)

2. A. Shukla, P. K. Garg, Global and Planetary Change, 190 (2020).

3. C. Huggel, A. Kääb, W. Haeberli, P. Teysseire, F. Paul, Canadian Geotechnical Journal, 39(2), 316-330 (2002)

4. V. B. Aizen, V. A. Kuzmichenok, A. B. Surazakov, E. M. Aizen, Global and Planetary Change, 56(3-4), 328-340 (2007)

5. U. Kamp, M. Byrne, T. Bolch, Journal of Mountain Science, 8(3), 374-389 (2011)

6. D.Scherler, B. Bookhagen, M. R. Strecker, Nature Geoscience, 4(3), 156-159 (2011)

7. V. G. Konovalov, V. A. Rudakov, Technique and technologies, 8, 98-107 (2015)

8. R. A. Chernov, A. Ya. Murav'ev, Ice and Snow, 58 (4), $462-472$ (2018)

9. K. V. Chistyakov, D. A. Ganyushkin, Yu. N. Kurochkin, Ice and snow, 1 (129), 49-60 (2015)

10. Ultra-high-resolution Space survey systems [Electronic resource] URL: https://innoter.com/articles/kosmicheskie-semochnye-sistemy-sverkhvysokogorazresheniya/ (accessed: 20.04.2020)

11. Landsat-8 [Electronic resource] URL: https://ru.wikipedia.org/?oldid=99374656.\%2099374656 (date accessed: 24.03 .2020 )

12. M. V. Volkodaeva, Ya. A. Volodina, A. Yu. Lomtev, S. N. Noskov, Russian Arctic, 6, 34 (2019)

13. A. M. Chandra, S. K. Gosh, A. V. Kiryushina, Remote sensing and geographical information systems (Technosphere, Moscow, 312, 2008)

14. V. G. Kobernichenko, Radio-Electronic systems of remote sensing of the Earth: textbook $(220,2016)$

15. J. G. Masek, E. F. Vermote, N. E. Saleous, R. Wolfe, F. G., Hall, K. F. Huemmrich, F. Gao, J. Kutler, T. Lim, IEEE Geoscience and Remote Sensing Letters, 3(1), 68-72 (2006)

16. T. G. Farr, P. A. Rosen, E. Caro, et al., Reviews of Geophysics, 45(2) (2007)

17. J. Verbesselt, R. Hyndman, G. Newnham, D. Culvenor, Remote Sensing of Environment, 114(1), 106-115 (2010)

18. J. W. Waters, L. Froidevaux, R. S. Harwood, et al., IEEE Transactions on Geoscience and Remote Sensing, 44(5), 1075-1092 (2006) 